\title{
Development and testing of an intelligent hybrid polymeric composite beam embedded with Ni-Ti shape memory alloy with crack growth retarding ability
}

\author{
W. M. Mwita* and A. N. Mtawa \\ Department of Mechanical Engineering, Mbeya Institute of Science and Technology, P. O. Box 131 Mbeya, \\ United Republic of Tanzania. \\ Accepted 14 September, 2012
}

\begin{abstract}
Hybrid Polymeric Composites (HPC) structural materials pose a challenge of developing microcracks and delaminations under impact and dynamic loads. This paper presents the development and testing of an Intelligent Hybrid Polymeric Composite (IHPC) beam embedded with Ni-Ti Shape Memory Alloy (SMA) with crack growth retarding ability. Upon heating to austenite finish temperature $\left(\mathrm{A}_{f}\right)$, Ni-Ti SMA wire contracts as a result of detwinned martensite-austenite phase transformation. The contraction of the SMA was utilized to stiffen and retard crack growth in the IHPC beam, hence resulting to an increase of mode I fracture stress intensity factor $\left(K_{\mathrm{IC}}\right)$. The SMA wire specimens were aged at $250^{\circ} \mathrm{C}$, then prestrained at $3 \%$ in order to stabilize austenite start $\left(A_{s}\right)$ and austenite finish $\left(A_{f}\right)$ transformation temperatures. The values of $A_{s}$ and $A_{f}$ for Ni-Ti SMA were determined. The IHPC and Polymeric Virgin (PV) notched beams were fabricated from epoxy resin. A four point bending test was performed on the beams to determine the effect of actuated Ni-Ti SMA on mode I fracture stress intensity factor $K_{\mathrm{IC}}$. The test was done at two temperatures, at T1 (below $\left.A_{s}\right)$ and at T2 $\left(A_{f}\right)$. Results showed that actuation of the $\mathrm{Ni}$-Ti SMA increased the value of $K_{\mathrm{IC}}$ for IHPC beams at T2 by $189 \%$ over the value of $K_{\mathrm{IC}}$ for PV beams at T1. Actuation of the Ni-Ti SMA increased the value of $K_{1 C}$ for IHPC beams at T2 by $41 \%$ over the value of $\mathrm{K}_{\mathrm{IC}}$ for IHPC beams at T1. Results showed that at T1 the loaded PV and IHPC beams fractured with unsteady crack propagation, while at T2 the loaded IHPC beams fractured with steady crack propagation. An increased value of $\mathrm{K}_{\mathrm{IC}}$ and steady crack propagation at T2 indicated that the SMA improved the crack retarding ability of the HPC beam.
\end{abstract}

Key words: Intelligent hybrid polymeric composite, shape memory alloy, stress intensity factor, crack growth, crack retardation.

\section{INTRODUCTION}

Hybrid polymeric composites (HPC) are materials that result from a combination of either polymer and polymer or polymer and non polymer chemically distinct materials with a distinct interface separating the components. The HPC material possesses desirable properties that cannot be achieved by any of the individual components of the composite (Trask and Bond, 2006; Collister, 2003). Hybrid polymeric composites being characterized by high

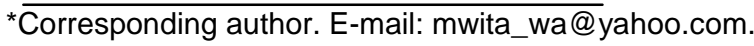

corrosion resistance, high strength to weight ratio and relatively poor thermal and electrical conductance are widely used for the design of aerospace, automobile and civil engineering structures (Auricchio et al., 2003).

One of the major challenges posed by HPC material structures is their brittle nature, when subjected to impact and dynamic loads, these materials undergo micro cracking and delaminations. The cracks coalesce, propagate and can lead to catastrophic failure (Kessler et al., 2003). The cracks can be difficult to detect and even difficult to repair. Currently, some cracks formed in the composite parts and structures can be inspected 


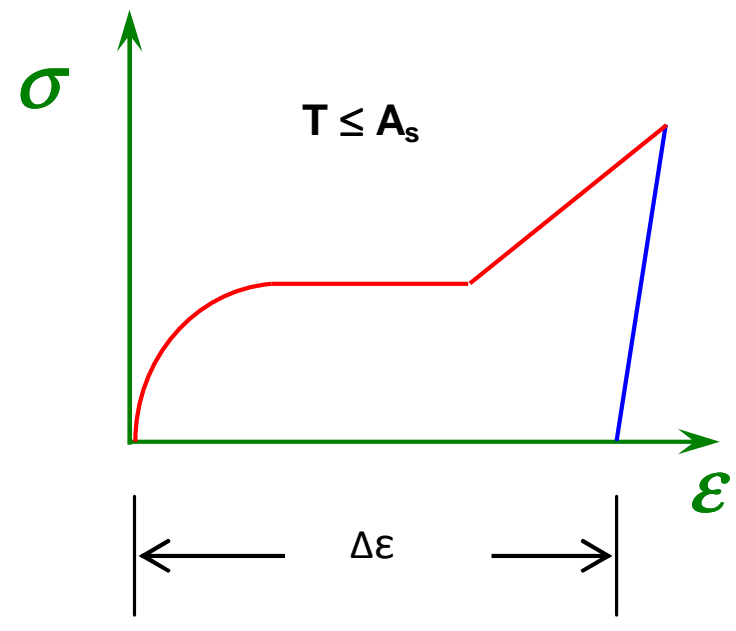

Figure 1. Shape Memory Effect, stress-strain behaviour of the Ni-Ti SMA.

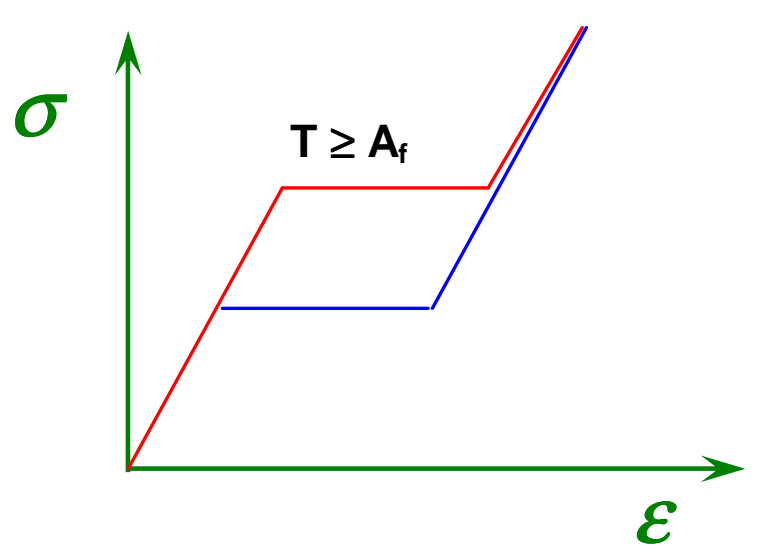

Figure 2. Pseudo Elasticity Effect, stress-strain behaviour of the Ni-Ti SMA.

manually to determine the extent of damage. For critical parts, advanced non destructive testing methods such as, ultrasonic, infrared thermography, X-ray tomography and computerized systems of vibro thermography can be used. The brittle nature of HPC structures makes them unpredictable in service and thus limits their overall integration and performance. There has been a need to develop an "intelligence" to these structures that can enhance crack growth retarding ability to overcome unpredictable fracture due to their brittleness.

In this paper, the development and testing of an intelligent hybrid polymeric composite (IHPC) beam embedded with $\mathrm{Ni}$-Ti shape memory alloy (SMA) with crack growth retarding ability is presented. The intelligence for crack growth retardation in the IHPC beam was induced by the embedded Ni-Ti SMA.

The SMA contracts as a response to applied electric current resistive heat. Contraction of the Ni-Ti SMA stiffens the IHPC beam and enduces crack growth retarding ability. The crack growth retarding ability of the IHPC beam was quantitatively tested through determination of the fracture stress intensity factor $\mathrm{K}_{\mathrm{IC}}$ of the notched IHPC beams under bending load at the Ni-Ti SMA austenite finish temperature $\left(A_{f}\right)$.

\section{Shape memory alloys (SMA)}

Shape memory alloys are material alloys with ability to undergo large strains while recovering their initial configuration at the end of the deformation process spontaneously or by heating without any residual deformation (Michaud, 2004; Lu and Weng, 1997). The memory phenomena of SMAs are associated with a solid-solid phase transformation which can be stress or thermally induced (Wenyi et al., 2002; Tsoi et al., 2003). Depending on the loading temperature, the memory of the SMA is accomplished either by the Shape Memory Effect (SME) or by Pseudo Elasticity Effect (PEE) in which the SMA gains extreme large compressive recovery stress (Neemat-Nasser and Wei-Guo 2006).

\section{SME of Ni-Ti SMA}

Consider a stress-strain diagram (Figure 1) for Ni-Ti SMA wire, at a relatively lower temperature than the austenite start $\left(A_{s}\right)$ and subjected to an external load beyond the elastic limit, the initial parent phase (twinned-martensite) denoted by $M[t]$ transforms into (detwinned-martensite) phase denoted by $\mathrm{M}[\mathrm{d}]$ accompanying an apparent macroscopic plastic deformation. Upon unloading, the material may remain in the detwinned martensite state with residual deformation $\Delta \varepsilon$. When the material is heated to a certain temperature, the detwinned-martensite transforms to austenite with the material recovering the residual deformation. This process is termed as the SME and it accompanies a reduction in macroscopic deformation. The critical temperature at which the detwinned martensite transforms to austenite is the austenitic start temperature $\left(A_{s}\right)$, and the temperature at which all the de-twinned martensite fully transforms to austenite is termed as the austenitic finish temperature $\left(A_{f}\right)$. Upon cooling, the austenite transforms back to original twinned-martensite. The critical temperature at which austenite transforms to martensite is termed as martensite start temperature $\left(\mathrm{M}_{\mathrm{s}}\right)$, and the temperature at which all the austenite fully transforms to martensite is termed as the martensite finish temperature $\left(\mathrm{M}_{\mathrm{f}}\right)$ (Bhattacharyya and Lagoudas, 1997).

\section{PEE of Ni-Ti SMA}

Consider a stress-strain diagram (Figure 2) of the parent $\mathrm{Ni}$-Ti SMA material in the austenite phase. When loaded 
at a temperature relatively higher than the austenite finish $\left(A_{f}\right)$, the material will perform elastically until certain yielding value of stress is reached. The austenite will now transform to detwinned martensite and again induce an apparent macroscopic plastic deformation. But detwinned martensite phase is not stable at this temperature, consequently, the martensite phase will transform in reverse to austenite during partial unloading while recovering the prior deformation. Upon complete unloading, the material returns to its original austenite state and all deformation is recovered. This extraordinary recoverable deformation behaviour is called super elasticity or pseudo elasticity, because in the loadingunloading process, material restores its original state and a hysteresis loop occurs (Muller and Seelecke, 2001).

\section{Methods for arresting/healing cracks in polymeric composites}

Fusion of the failed surfaces has been one of the methods of healing cracks in polymeric composites. In this method, polymeric composite materials possessing selective cross-links between polymer chains that can be broken by applied forces and then reformed by heat or pressure have been reported to offer a significant healing efficiency (Chen et al., 2002). The use of a thermoplastic healing agent into a damaged thermosetting epoxy to produce a homogeneous matrix has been developed by Zako and Takano (1999), the method offered the capacity for self healing, but it requires means of damage sensing, some form of response via feedback loops and heating systems.

The use of hollow glass fibers for storing the healing resin embedded in a composite laminate was experimented by Bleay et al. (2001). The method requires large diameter of the fibers, needs the fiber to fracture and release the healing resin to the crack location and also the need to maintain the low viscosity of the healing resin to facilitate fiber and damage infusion. Kesler et al. (2003) developed a self healing of an epoxy composite in which arrest and retardation of cracks were achieved by microencapsulated dicyclopentadiene (DCPD) agent and Grubbs' first generation Ru catalyst. This method lacked adequacy of the catalyst supply to provide uniform bridging of the crack. Also, some voids were created in the composite after the healing resin was consumed. Lee et al. (2004) considered healing of polymers using nano particles dispersed in polymer films to behave at the damaged site in a similar fashion to blood clotting. However, the healing capacity of this method was limited to miniature scale.

The use of shape memory alloys for healing cracks in polymeric composites has been reported to offer a significant healing ability. In this method, the reverse transformation of the SME (upon heating) and the energy dissipation due to the PEE produces actuation forces that could be harnessed to heal the deformed polymeric composite structures. Thompson and Loughlan (2001) utilized $\mathrm{Ni}-\mathrm{Ti}$ actuators in controlling buckling and post buckling of the plate by positioning the SMA wires in the tubes, the tubes were embedded in the composite matrix. The wires were constrained between the boundaries. The method aimed at insuring that there is no direct interface between the SMA wires and the matrix hence reducing debonding. The performance of the adaptive composite was successful. The limitation of this approach was that the loading planes or axes of the SMA and the matrix may not coincide, hence the matrix lacks an effective healing by the SMA recovery force. It has a limited application to conventional designs.

Burton et al. (2006) did a finite element simulation on a self healing composite using $\mathrm{Ni}-\mathrm{Ti}$ shape memory alloy. In this study, SMA wires were not embedded in the metal matrix to avoid debonding, instead they were fixed on the surfaces of the matrix. Healing of the composite was achieved by simple heating of SMA wires that reverses transformation of martensite to austenite of $\mathrm{Ni}-\mathrm{Ti}$ wires. This brought the crack faces into contact. However, fixing SMA wires on the surface of the matrix may have little practical application to polymeric composites structures.

Various literatures show that performing thermomechanical treatment on SMAs improves their actuation performance. The recovery stress generated by the SMA increases with increase of the SMA prestrain and the maximum recovery stress can be obtained at the prestrain range of 3 to $6 \%$ (Neemat-Nasser and Wei-Guo 2006; Huang, 1998; Miller and Lagoudas, 2001). Other studies have shown that aging and annealing of the SMA can lower and stabilize the austenite start $\left(A_{s}\right)$ and austenite finish $\left(A_{f}\right)$ transformation temperatures (Mukhawana, 2005).

One of the factors for failure of the smart composite materials is the fiber-matrix interfacial debonding (Gao, 1988). It has been recommended that the working temperature of the Ni-Ti SMA actuator should not exceed the glass transition temperature $\left(T_{g}\right)$ of the matrix material. To avoid this, intermittent supply of electric current during heating, the SMA is recommended (Umezaki, 2000).

In this paper, an Intelligent Hybrid Polymeric Composite (IHPC) beam was fabricated in which Ni-Ti SMA wire was embedded. SMA-matrix interfacial debonding was overcome by intermittent heating of the SMA. To stabilize $\mathrm{Ni}-\mathrm{Ti} \mathrm{SMA}$ austenite finish $\left(\mathrm{A}_{\mathrm{f}}\right)$ transformation temperature, the SMA wire specimens were aged at $250^{\circ} \mathrm{C}$ and then prestrained at $3 \%$.

\section{MATERIALS AND METHODS}

An experimental procedure was conducted in order to determine the ability of the IHPC beam to retard a crack growth. To achieve this, the following was done; selection of appropriate SMA material, thermo treatment and determination of transformation temperatures of the SMA wires. Fabrication of PV and IHPC notched beams.

Testing the beams to determine mode I fracture stress intensity 

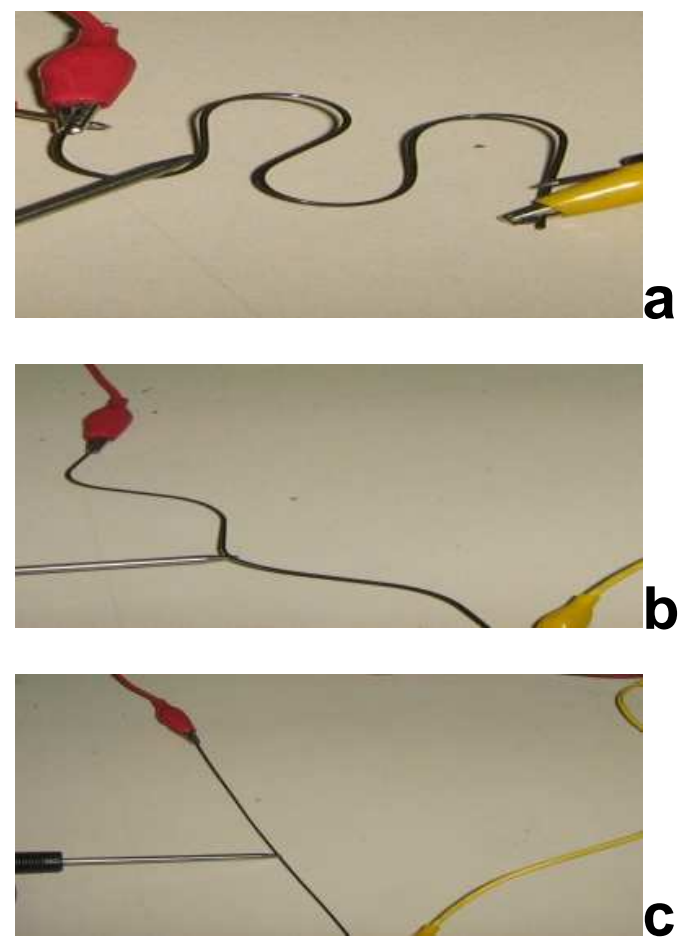

Figure 3. Determination of transformation temperatures of $\mathrm{Ni}-\mathrm{Ti}$ SMA wires. (a) Before dc current was applied to the SMA wire. (b) After $3 \mathrm{~A}$ DC current was applied to the SMA wires, it started to straighten at an average temperature of $30^{\circ} \mathrm{C}$. (c) The SMA wires became completely straight at an average temperature of $46^{\circ} \mathrm{C}$

factor $K_{I C}$ of the IHPC beam at austenite finish temperature $\left(A_{f}\right)$.

\section{Selection and treatment of $\mathrm{Ni}-\mathrm{Ti}$ SMA}

One milliliter diameter of $\mathrm{Ni}$-Ti SMA wire was used. Composition (Percentage by weight) of the $\mathrm{Ni}$-Ti SMA as obtained from the supplier was: Ni-55.32, Ti-44.38, C $\leq 0.05, \mathrm{O} \leq 0.05$ and others $(\mathrm{Al}$, $\mathrm{Co}, \mathrm{Cr}, \mathrm{Cu}, \mathrm{Fe}, \mathrm{Mn}, \mathrm{Mo}, \mathrm{Nb}, \mathrm{Si}, \mathrm{W})-0.2$. The material was purchased from Johnson Matthey, 1070 Commercial Street, Suite 110, San Jose, CA 95112, USA. The wire was cut into 35 pieces, $200 \mathrm{~mm}$ long each.

\section{Thermo treatment of Ni-Ti SMA}

$\mathrm{Ni}$-Ti SMA wires were heated in the furnace to a temperature of $250^{\circ} \mathrm{C}$ for $10 \mathrm{~h}$, and then they were left to cool in an ambient air. The heat treatment was aimed to release any residual stress and to stabilize the austenite start $\left(A_{S}\right)$ and austenite finish $\left(A_{f}\right)$ transformation temperatures. After heat treatment, the Ni-Ti SMA wires were prestrained by $3 \%$ on a tensile testing machine.

Prestraining of the $\mathrm{Ni}-\mathrm{Ti}$ SMA wires was aimed to induce detwinned martensite volume fraction, hence increasing the transformation strain and recovery force of the Ni-Ti SMA.

Prestraining of $\mathrm{Ni}-\mathrm{Ti}$ wires was carried out in the Strength Laboratory. The prestraining load was predetermined by loading two equal lengths of $\mathrm{Ni}-\mathrm{Ti}$ wire specimens up to fracture. After fracture, the load-extension curves were used to determine the load that could induce a plastic strain of $3 \%(4.5 \mathrm{~mm}$ apparentpermanent elongation) in the wire specimens with a gauge length of $150 \mathrm{~mm}$. A maximum average tensile force of $55 \mathrm{~N}$ was selected and was applied on each of the wire specimens. SMA specimens were prestrained by $3 \%$ on a gauge length of $150 \mathrm{~mm}$ using a $5 \mathrm{kN}$ load cell on a tensile testing machine. The test was conducted at $25^{\circ} \mathrm{C}$ room temperature at a displacement rate of $5 \mathrm{~mm} / \mathrm{m}$ in. A vernier caliper was used to measure the prestrained length of the wires.

\section{Determination of Ni-Ti SMA transformation temperatures}

An experiment was performed to determine transformation temperatures of prestrained $\mathrm{Ni}-\mathrm{Ti}$ SMA wires. Three 3 prestrained $\mathrm{Ni}$-Ti SMA wire specimens were bent into several irregular shapes (Figure $3 a$ ) at $26^{\circ} \mathrm{C}$ room temperature followed by applyin g electric current of $3 \mathrm{~A}$ to each wire consecutively. This was done by connecting each end to direct current (DC) source terminals. The surface temperature of the wire was measured using a digital thermometer. As the temperature of the wire increased, the wire started to straighten as it was trying to recover its original straight shape until it was completely straight (Figure $3 b$ and c). The temperatures at which the wire specimens started to straighten and at which they were completely straight were recorded. Results indicated that the SMA wire started to straighten at an average temperature of $30^{\circ} \mathrm{C}$. The specimens completely recover ed their straight shape at an average temperature of $46^{\circ} \mathrm{C}$. From these results, the austenite start $\left(A_{s}\right)$ and austenite finish $\left(A_{f}\right)$ temperatures for the $\mathrm{Ni}$-Ti SMA wire specimens were taken as 30 and $46^{\circ} \mathrm{C}$, respectively.

\section{Fabrication of IHPC and PV beams}

The fabricated notched beam specimens were of rectangular cross section with dimensions $150 \times 5 \times 10 \mathrm{~mm}$. The beam dimensions conform to the standard four point bending test (Measurements Group, 1982). Three notched PV beams (without SMA wire) and six notched IHPC beams were fabricated. In each of the IHPC beam, a $\mathrm{Ni}$-Ti SMA wire was embedded at $7 \mathrm{~mm}$ off the neutral axis to enhance effective stiffening of the beam against the bending moment induced by the external load.

Casting of the silicone mould was performed in the MK-Mini Vacuum Chamber in the Smart Materials Laboratory. The silicone used was Wicker Silicone grade Elastosil (EL) M 4644A coupled with Wicker hardener grade Elastosil (EL) M 4644B. The beam specimens were fabricated by casting 60D polyurethane thermosetting plastic epoxy resin in the silicon mould. The casting of the beams was done using the microchannel plate (MCP) vacuum cast system in the Rapid Prototyping Development Laboratory. The casting of each beam was performed by mixing epoxy resin and the hardener in the ratio of $1: 1$ by mass. Using a sharp razor blade, a $V$-notch of $2 \mathrm{~mm}$ deep with a notch-tip angle of $60^{\circ}$ was cut on the centre of each beam. The samples of notched beams are as shown in Figure 4. A crack length of $1 \mathrm{~mm}$ was cut at the notch-tip, giving the value of an initial crack length 'a' as $3 \mathrm{~mm}$. Details of the V-notch and the initial crack length are as shown in Figure 5.

Determining the stress intensity factor of PV and IHPC notched beams

\section{Four point bending test}

A four point bending test was performed to investigate the effect of 


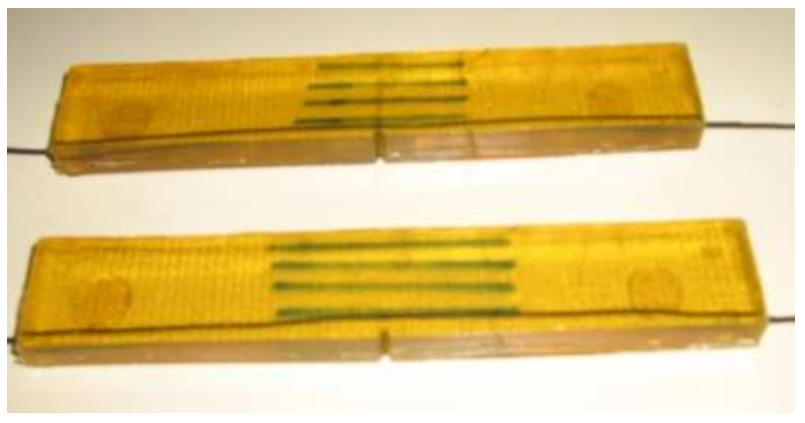

Figure 4. Manufactured IHPC beams.

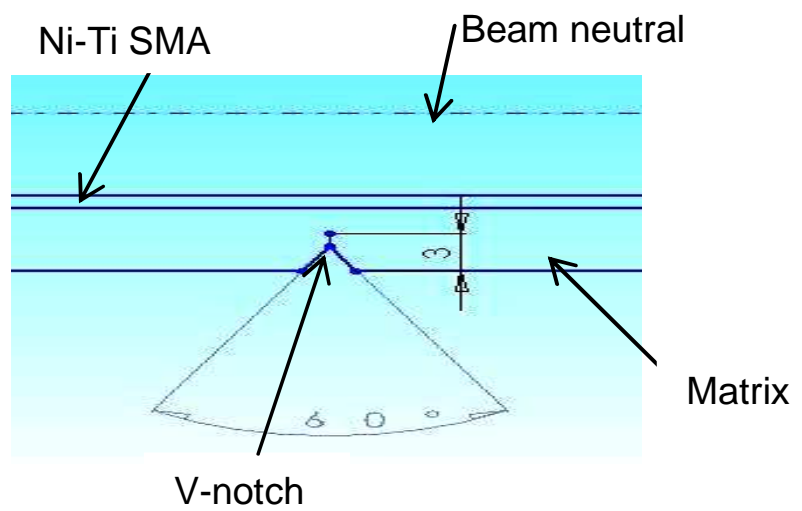

Figure 5. Detailed view of the V-notch with initial crack length of $3 \mathrm{~mm}$.

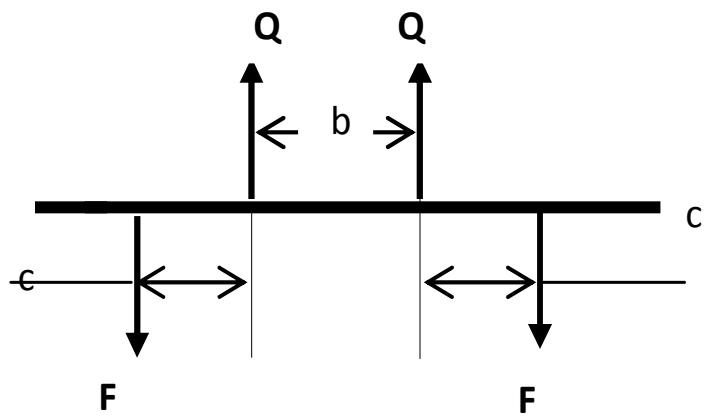

Figure 6. Four point bending load locations.

actuated Ni-Ti SMA on the mode I stress intensity factor $\mathrm{K}_{\mathrm{IC}}$ of the IHPC beams. A four point bending method was preferred due to the fact that in this type of bending, along the middle span on the beam specimen, the bending moment is uniform and the shear force is approximately zero. The location for the load points of notched IHPC and PV beams were chosen according to the guidelines of the American Society for Testing and Materials (ASTM) for the bending of single edge notched specimen. The beam thickness $\mathrm{H}$, beam width $B$ and the loading span $b$ are approximately related as:

$0.25 \mathrm{~B} \leq \mathrm{H} \leq 1 \mathrm{~B}$ and $\mathrm{B} \leq \mathrm{b} \leq 4 \mathrm{~B}$ (Broek, 1986). The beam was simply supported, loaded under four point bending. The beams load locations are as shown in Figure 6: the middle span length $b=30$ $\mathrm{mm}$, the outer span lengths $\mathrm{c}=30 \mathrm{~mm}$ each, the free ends lengths were $30 \mathrm{~mm}$ each. The test was performed in the Strength Laboratory.

A bending fixture was fabricated to suit the load locations of the beam as indicated in Figure 6 . The top member of the fixture was used for loading the beam and the bottom member of the fixture for supporting the beam. Metal bushes were used on each loading point to reduce friction forces between the fixture and the beam specimen. Four bolts were used to fix the bushes on members while maintaining a light clearance fit between the bush and the bolt. An assembly of the bending fixture with the beam is as shown in Figure 7.

\section{Test procedure}

Three IHPC and three PV notched beams were tested under a four point bending load, at room temperature $\mathrm{T} 1\left({ }^{\circ}{ }^{\circ} \mathrm{C}\right)$ and au stenite finish temperature T2 $\left(4^{\circ} \mathrm{C}\right)$. The layout of the four point bending test is as shown in Figure 8.

In order to measure the crack length induced by a given bending force, one face of each notched beam was marked with equally spaced parallel lines drawn longitudinally to the axis of the beam (Figure 4). A scale ruler was used to draw parallel lines equally spaced at $2 \mathrm{~mm}$ apart. Each line on the specimen was marked at its respective perpendicular length from initial crack tip. During the loading process, the instantaneous crack length was observed and recorded, simultaneously the corresponding bending force $F$, was recorded using the data acquisition unit.

At room temperature $\mathrm{T} 1$ of $24^{\circ} \mathrm{C}$, each of the three PV notched beams and three IHPC notched beams was subjected to a four point bending load. The test was performed using a $10 \mathrm{kN}$ load cell at a displacement rate of $1 \mathrm{~mm} / \mathrm{min}$. The load was increased until the crack started to propagate. The load was increased until the crack propagated across the width of the beam, up to a complete fracture. The corresponding values of the bending load, crack length and the transverse deflection of the beam were recorded continuously.

The next test was performed after the temperature of the $\mathrm{Ni}-\mathrm{Ti}$ SMA has been raised from T1 $\left(24^{\circ} \mathrm{C}\right)$ to $\mathrm{T} 2\left(4^{\circ} \mathrm{C}\right)$ in orde $r$ to transform the detwinned martensite to austenite. The Ni-Ti SMA wire was actuated by direct current resistive heating. A magnitude of $3 \mathrm{~A}$ of electric current was supplied by the DC source for the purpose. While at temperature T2, the bending load was applied on each of the three notched IHPC beams. The load was increased until the crack propagated across the width of the beam. The values of the bending load, the transverse deflection of the beam and the crack length were recorded continuously. The average experimental results for three beams at each temperature were used to determine the stress intensity factor $K_{l}$ and the fracture stress intensity factor $K_{\mathrm{IC}}$. The fracture stress intensity factor $\mathrm{K}_{\mathrm{IC}}$ is the value of stress intensity factor for which the crack becomes unstable and propagates completely across the beam until fracture.

Applying Irwin's mathematical model on a specimen with finite size under plane stress, the mode I stress intensity factor $K_{I}$ near the crack tip is obtained by Equation 1:

$\mathrm{K}_{\mathrm{l}}=\sigma \mathrm{Y}(\mathrm{a})^{1 / 2}$

where $\sigma$ is the bending stress in the beam (for the beam under bending load), $a$ is crack length, $B$ is un-cracked width in the crack plane, $\mathrm{Y}$ is the dimensionless compliance polynomial function of the ratio $\mathrm{a} / \mathrm{B}$.

The compliance function $Y$ can be expressed as Equation 2:

$\mathrm{Y}=\mathrm{A}(\mathrm{a} / \mathrm{B})^{1 / 2}-\mathrm{F}(\mathrm{a} / \mathrm{B})^{3 / 2}+\mathrm{C}(\mathrm{a} / \mathrm{B})^{5 / 2}-\mathrm{D}(\mathrm{a} / \mathrm{B})^{7 / 2}+\mathrm{E}(\mathrm{a} / \mathrm{B})^{9 / 2}$ 


\section{Loading member}

\section{$8 \mathrm{~mm}$ diameter x4 bush}
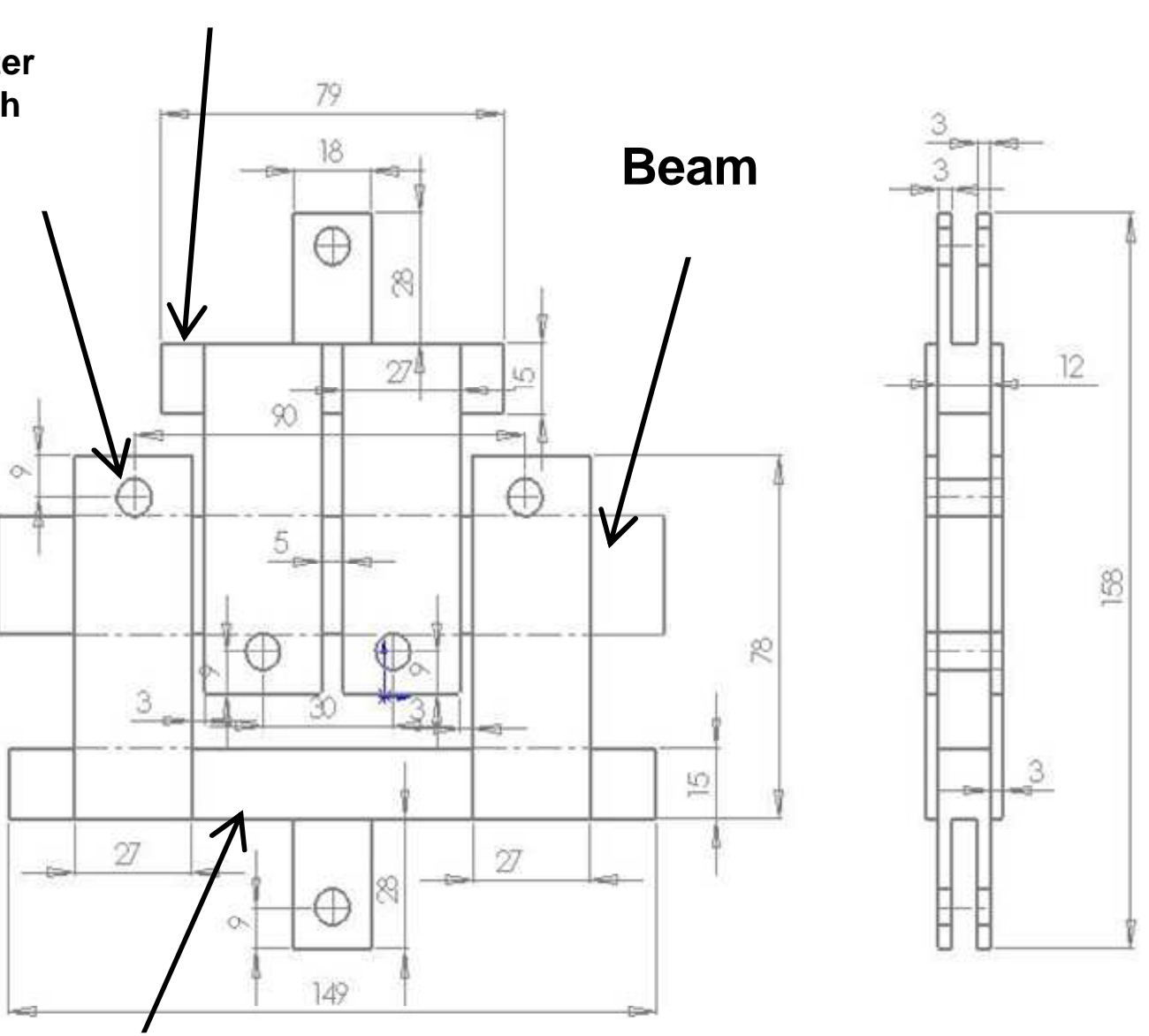

\section{Supporting member}

Figure 7. An assembly of the bending fixture with the beam (all dimensions in $\mathrm{mm}$ ).

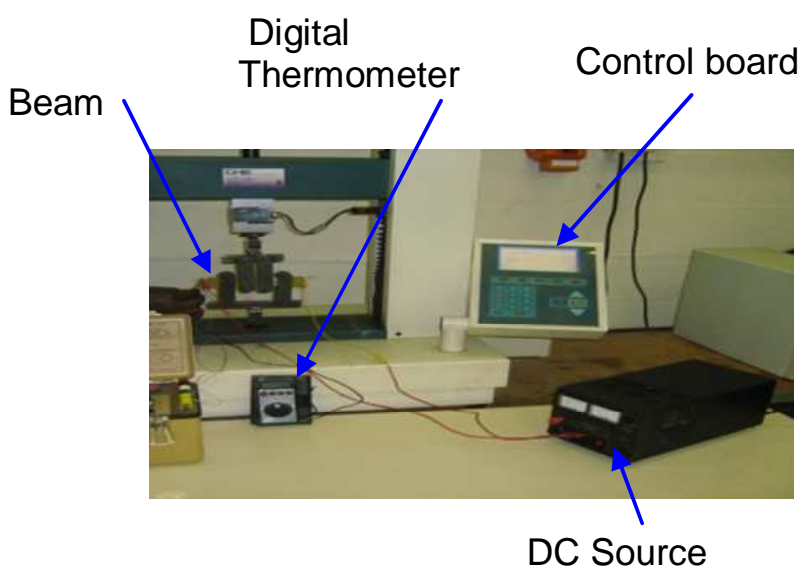

Figure 8. Layout of a four point bending test for IHPC and PV beams.
For a four point bending, the constants $\mathrm{A}, \mathrm{F}, \mathrm{C}, \mathrm{D}$ and $\mathrm{E}$ are 1.99 , $2.47,12.97,23.17$ and 24.80 , respectively (Hearn, 1997).

Therefore, the equation for stress intensity factor can be written as Equation 3:

$\mathrm{K}_{\mathrm{l}}=\left(3 \mathrm{~Pb} / \mathrm{HB}^{3 / 2}\right) \mathrm{Y}$

where $P=2 Q=$ total bending load on the beam, $b$ is the distance between loading points, $\mathrm{H}$ is the beam specimen thickness.

The fracture stress intensity factor $\left(\mathrm{K}_{\mathrm{IC}}\right)$ is obtained when the fracture load $\left(\mathrm{Q}_{\mathrm{c}}\right)$ and crack length $(\mathrm{a}=\mathrm{B})$ at fracture are substituted in Equation 3.

\section{RESULTS}

The measurements of the four point bending test performed on the notched IHPC and PV beams were tabulated and plotted as shown in Figures 9, 10 and 11. 


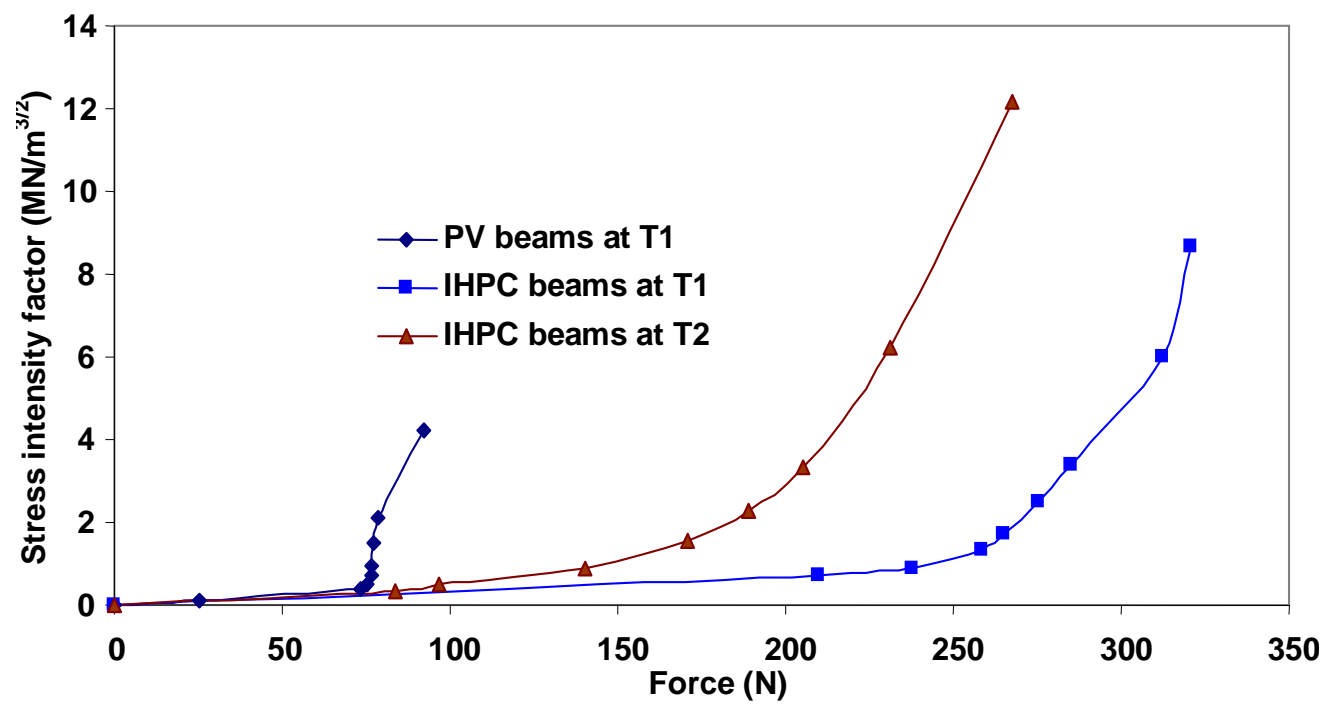

Figure 9. Stress intensity factor versus bending force of the notched IHPC and PV beams.

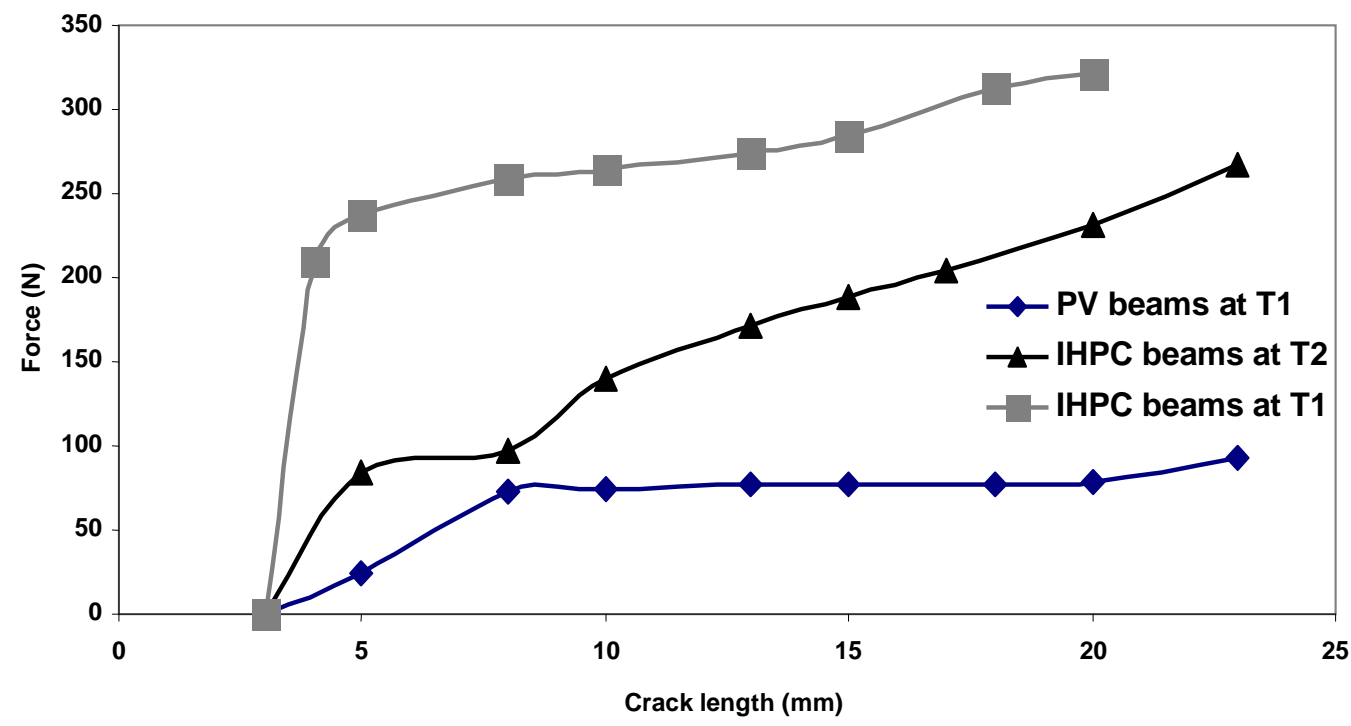

Figure 10. Bending force versus crack length of the notched IHPC and PV beams.

The results for the bending force versus stress intensity factor (Figure 9) showed that the PV beams loaded at temperature $T 1$ below austenite start $\left(A_{S}\right)$ fractured at a force of $93 \mathrm{~N}$ with a corresponding critical stress intensity factor $\mathrm{K}_{\mathrm{IC}}$ of $4.21 \mathrm{MN} / \mathrm{m}^{3 / 2}$. The IHPC beams loaded at a temperatureT1 fractured at a force of $321 \mathrm{~N}$ with a corresponding critical stress intensity factor $\mathrm{K}_{\mathrm{IC}}$ of 8.64 $\mathrm{MN} / \mathrm{m}^{3 / 2}$. When the IHPC beams were loaded at a temperature T2 (austenite finish $A_{f}$ ), the beams fractured at a force of $268 \mathrm{~N}$ with a corresponding critical stress intensity factor of $12.17 \mathrm{MN} / \mathrm{m}^{3 / 2}$.
The bending load versus crack length (Figure 10) showed that at temperature $\mathrm{T} 1$, the bending load-crack length graph for the notched PV beams behaved linearly up to a force of $75 \mathrm{~N}$, after which the crack propagation was unsteady and it continued to propagate at approximately constant bending load up to fracture. At $\mathrm{T} 1$, the notched IHPC beams graph showed a linear curve up to a force of $225 \mathrm{~N}$, after which the crack was unsteady and propagated at a small increase of the bending load up to fracture. At temperature T2, the notched IHPC beams showed approximately a linear curve with steady crack 


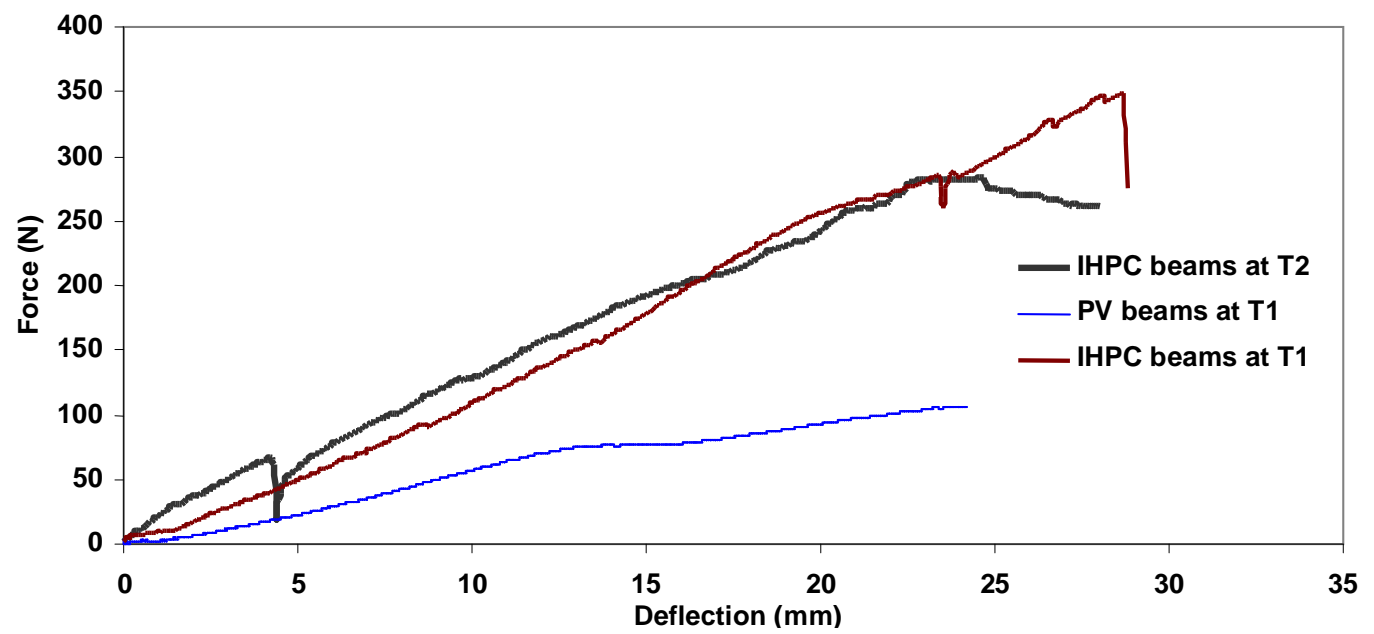

Figure 11. Bending force versus deflection of the notched IHPC and PV beams.

propagation up to a fracture load of $268 \mathrm{~N}$. Considering the load versus deflection graph in Figure 11, it was noted that within the loading range of 0 to $200 \mathrm{~N}$, heating the Ni-Ti SMA wire to T2 increased the load on the IHPC beams by $20 \%$ over the load on the IHPC beams at T1. Beyond $200 \mathrm{~N}$ force, the load at T2 was lower than that at T1.

\section{DISCUSSION}

In reference to Figure 9, the value of fracture stress intensity factor $\left(\mathrm{K}_{\mathrm{IC}}\right)$ for IHPC beam at a temperature of austenite finish (T2) was $41 \%$ more than that at temperature below austenite start (T1). It can also be noted that the value of $\mathrm{K}_{\mathrm{IC}}$ for the IHPC beam at austenite finish temperature (T2) was $189 \%$ more than that of $\mathrm{PV}$ beam at temperature below austenite start (T1). An increase of $K_{I C}$ for the IHPC beam was likely due to the fact that heating the embedded $\mathrm{Ni}-\mathrm{Ti}$ SMA induces compressive stress in the composite; hence, increases resistance of the beam to the crack fracture.

The results for bending stress versus crack length (Figure 10) at temperature (T1), the linear-curve load increased from $75 \mathrm{~N}$ for PV beam to $225 \mathrm{~N}$ for IHPC beam. This is assumed that embedded SMA wire in the composite increased the resistance to crack propagation. At austenite finish temperature (T2), there was stable crack propagation and an increase for the linear-curve load for IHPC beam to $268 \mathrm{~N}$. The stability of the crack growth in the beam was a result of induced compressive recovery stress of the actuated (heated) Ni-Ti SMA.

Results for bending load versus deflection plotted in Figure 11 can be explained as an increase of the load within the loading range of 0 to $200 \mathrm{~N}$ for the IHPC beam at T2 was due to the compressive recovery force generated by the actuated Ni-Ti SMA. As it was noted, beyond the $200 \mathrm{~N}$, the load on the IHPC beam at T2 was lower than that at $\mathrm{T} 1$, the reason for this is assumed to be due to softening and debonding of the SMA-matrix interface upon heating the Ni-Ti SMA.

The use of Ni-Ti SMA for retarding crack propagation in a polymeric composite developed in this work is more practical as compared to the previous methods such as fusion of polymers using healing resins and simulation of SMA-polymer healing as reported in the literature.

\section{Conclusion}

The results achieved in this work indicate that application of the Ni-Ti SMA into a hybrid polymeric composite beam generated a significant recovery stress that on its turn induced a compressive stress in the matrix. As a result, increased the fracture stress intensity factor $\mathrm{K}_{\mathrm{IC}}$ of the HPC beam. The embedded Ni-Ti SMA contracted, hence significantly enhanced the crack growth retardation ability. The results promise that the use of shape memory alloy can improve in-service safety and reliability of the hybrid polymeric composites and structures. Although, the SMA actuation temperature was kept below the glass transition temperature of the epoxy 60D matrix, to some extent stiffening of the IHPC beam was limited by the SMA-matrix interfacial debonding. More research on the control of interfacial debonding has to be done.

\section{ACKNOWLEDGEMENTS}

The authors would like to express their sincere appreciation to Professor $\mathrm{O}$. Philander for his professional guide and advice and for the permission to 
use the Smart Materials Laboratory at Cape Peninsula University of Technology (South Africa) for most of the experimental work. Also, the authors thank Mr. D. Brent for the permission to use the Industrial Engineering Laboratory at Stellenbosch- University (South Africa) for fabrication of beam specimens.

\section{REFERENCES}

Auricchio F, Marfia S, Sacco E (2003). Modelling of SMA materials: training and two way memory effects. Comput. Struct. 81:23012317.

Bhattacharyya A, Lagoudas DC (1997). A stochastic thermodynamic model for the gradual thermal transformation of SMA polycrystals. J. Solids Struct. 6:235-250

Bleay SM, Loader CB, Hawyes VJ, Humberstone L, Curtis PT (2001). A smart repair system for polymer matrix composites. Composites $A$. 32:1767-1776.

Broek D (1986). Elementary Engineering Fracture Mechanics, fourth revised edition, Kluwer Academic Publishers, Dordrecht. pp. 179 181.

Burton DS, Gao X, Brinson LC (2006). Finite element simulation of selfhealing shape memory alloy composite. Mech. Mater. 38:525-537.

Chen X, Dam MA, Ono K Mal AK, Shen H, Nutt SR, Sheran K, Wudl F (2002). A. Thermally Remendable Cross-Linked Polymeric composites. Mater. Sci. 295(5560):1698-1702.

Collister WD Jr (2003). Material Science and Engineering, an introduction, sixth edition. USA, John Wiley \& Sons. pp. 451- 566.

Gao YC (1988). Fracture of fiber-reiforced materials. J. Appl. Math. Phys. (ZAMP) 39:551-572.

Hearn EJ (1997). Mechanics of Materials 2, Third Edition-ButterWorthHeinemann.

Huang W (1998). Effects of internal stress and martensite variants on phase transformation of $\mathrm{Ni}-\mathrm{Ti}$ shape memory alloy. J. Mater. Sci. Lett. 17(184):3-4.

Kessler MR, Sottos NR, White SR (2003). Self healing structura composite materials. Composites Part A: Appl. Sci. Manuf. 34(8):743-753.

Lee JY, Buxton GA, Balazs AC (2004). Using nano particles to create self healing composites J. Chem. Phys. 121(11):5533-5540.

Lu ZK, Weng GJ (1997). Martensitic transformation and stress-strain relations of shape memory alloys. J. Solids 45:1905-1928.
Measurements Group (1982). Tech Note. Calibration of Photoelastic Plastics for Two and Three - Dimensional Modal Analysis- TN705 page 5. Measurements Group, INC Raleigh, North Carolina 27611, USA.

Michaud V (2004). Can shape memory alloy composites be smart? Scripta Materialia 50:249-253.

Miller DA, Lagoudas DC (2001). Influence of cold work and heat treatment on the shape memory effect and plastic strain development of Ni-Ti. Mater. Sci. Eng. A. 308:161-175.

Mukhawana MD (2005). Effects of thermo-mechanical cycling and aging on quasi-plastic material response exhibited by $\mathrm{Ni}$-Ti shape memory alloys. (M. Tech Thesis).

Muller I, Seelecke S (2001). Thermodynamic aspect of shape memory alloys. Math. Comput. Model. 34(12-13):1307-1355.

Nemat-Nasser S, Wei-Guo G (2006). Super elastic and cyclic response of NiTi SMA at various strain rates and temperatures. Mech. Mater. 38:463-474

Thompson SP, Loughlan J (2001). Enhancing the post-buckling response of a composite panel structure utilising shape memory alloy actuators- a smart structural concept. Compos. Struct. 51:2136.

Trask RS, Bond IP (2006). Biomimetic self-healing of advanced composite structures. Smart Mater. Struct. 15:704-710.

Tsoi KA, Schrootenand J, Stalmans R (2003). Part I: Thermo mechanical characteristics of shape memory alloys. Mater. Sci. Eng. A. 368:286-298.

Umezaki $E$ (2000). Improvement in separation of SMA from matrix in SMA embedded structures. Mater. Sci. Eng. A, 285:363-369.

Wenyi Yan, Chun Hui Wang, Xin Ping Zhang, Yin-Wing Mai (2002) Effect of transformation volume contraction on the toughness of super elastic shape memory alloys. Smart Mater. Struct. 11(6):947987.

Zako M, Takano N (1999). Intelligent material systems using epoxy particles to repair microcracks and delamination damage in GFRP. J. Intell. Mater. Syst. Struct. 10(10):836-841. 